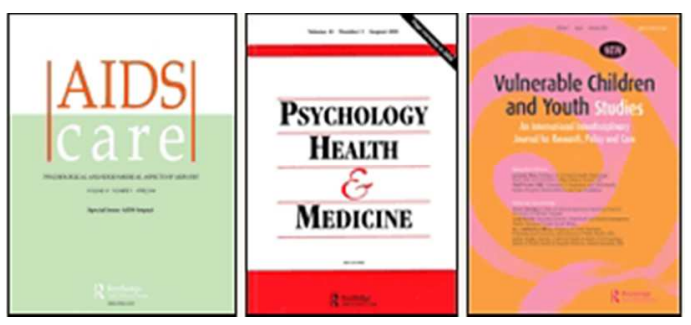

The Relative Importance of Avoidance and RestorationOriented Stressors for Grief and Depression in Bereaved Parents

\begin{tabular}{|r|l|}
\hline Journal: & $\begin{array}{l}\text { AIDS Care - Psychology, Health \& Medicine - Vulnerable Children and Youth } \\
\text { Studies }\end{array}$ \\
\hline Manuscript ID: & Draft \\
\hline Journal Selection: & Psychology, Health \& Medicine \\
\hline Keywords: & grief, bereavement, parent, death of a child, depression \\
\hline \multicolumn{2}{|r}{} \\
\hline
\end{tabular}




\title{
The Relative Importance of Avoidance and Restoration-Oriented Stressors for Grief and Depression in Bereaved Parents
}

\begin{abstract}
Background

Previous research has identified a number of individual risk factors for parental bereavement including the sex of the parent, the sex of the child, avoidance-focussed coping style and time since death. These factors emerged from research where variables were tested univariately and their relative importance is currently unknown. The current research therefore aims to investigate which risk factors are important, multivariately, for the outcomes of grief and depression in parents following the death of their child.
\end{abstract}

\section{Method}

Psychosocial measures were completed by 106 bereaved parents four years post-loss recruited from death records in Scotland. The cause of the child's death included long term illness and stillbirths as well as sudden and violent deaths.

\section{Results}

In multivariate regression analyses, depression was predicted by avoidance-focussed coping and the number of restoration-oriented stressors. Grief was predicted by avoidance, restoration stressors and level of continuing bonds.

\section{Conclusion}

The present study adds to the knowledge about the phenomenon of parental bereavement with participants recruited directly from death records rather than through 
support, clinical or obituary sources. Factors previously found to be associated with outcomes when tested univariately such as sudden, violent death or sex of the parent are not necessarily important when tested multivariately. This study highlights that different vulnerability factors exist for grief and depression in bereaved parents. 


\section{Introduction}

The Integrated Risk Factor Framework described by Stroebe, Folkman, Hansson \& Schut (2006) indicates that bereavement outcomes are affected by factors from a number of different domains. For bereaved parents, grief has been found to be associated with time since death (Anderson, Marwit, Vandenberg, \& Chibnall, 2005; Feigelman, Gorman, \& Jordan, 2009; Robinson \& Marwit, 2006), emotional coping and avoidance coping (Anderson et al., 2005; Robinson \& Marwit, 2006), social support and subsequent stressors (Hazzard, Weston, \& Gutterres, 1992) and the sex of the parent, with mothers experiencing higher levels of grief than fathers (Bohannon, 1991; Littlefield \& Silverman, 1991). Losing a male child was linked with higher levels of depression (Hazzard et al., 1992; Robinson \& Marwit, 2006) as was the death being sudden (Hazzard et al., 1992) or the child being healthy prior to their death (Littlefield \& Silverman, 1991). Finally, ruminative coping was found to be associated with higher levels of depression (Ito et al., 2003; Nolen-Hoeksema, Parker, \& Larson, 1994). Although most of these factors were found to be associated with levels of depression or grief when tested univariately, the relative importance of each when compared collectively in multivariate analyses has not yet been established.

In addition to symptoms of grief, the bereaved may also be experiencing significant levels of depressive symptoms following the loss of a loved one (Stroebe, Schut, \& Stroebe, 2007). The factors associated with depressive symptoms may be different from those associated with grief and are, therefore, worthy of investigation (Wijngaards-de-Meij et al., 2005).

The grief experienced by bereaved parents is thought to reduce from the time of bereavement until about three years, when an often unexpected increase in emotional distress is experienced (Rando, 1983). After this time, the parent is believed to experience a further improvement in bereavement-related outcomes over time. By four years post-loss, the parent 
is thought to have lived through the worst times of their loss and should be making a recovery in terms of negative symptoms. This period of mid-bereavement, when bereaved parents are believed to be moving towards resolution of their grief, is therefore of considerable interest to researchers (Rando, 1983).

The present study was exploratory in nature and aimed to identify which factors were most closely associated with grief and depression in a group of bereaved parents demonstrating high levels of grief and depression. Measures of outcomes, interpersonal, intrapersonal, loss and restoration-oriented stressors were taken at around four years postloss. Restoration-oriented stressors were having difficulties at work, financial or relationship difficulties, worries about how other members of the family coping, house move, experiencing other bereavements or having difficulty caring for surviving siblings, derived from earlier qualitative research identifying issues that bereaved parents were coping with following the loss of their child (Harper, O’Connor, Dickson and O'Carroll, 2009). The number of stressors experienced was reported in absolute terms, giving a possible range of restoration-oriented stressors from zero to seven.

\section{Method}

Ethical approval for the study was granted by the ethics committee of the Psychology Department at the University of Stirling. The project was also approved and supported by The General Register Office for Scotland (GROS).

\section{Participants}

The GROS provided a list of death records for people who died in Scotland in 2005, aged from 0 to 30 years, and those who were stillborn. The number of bereaved parents in the population group was 2033. Letters were intended to be posted out over a two-week period in two batches, with 1148 (56\%) posted in the first batch. Arising from this mailing, twelve 
complaints were received, mostly relating to the use of personal details; these potential respondents were not aware that their details were in the public domain. Although the number of complaints was small ( $1 \%$ of the total letters sent) the level of distress that was experienced by these people was significant. Consequently, the research team took the decision not to send out any further invitations in order to avoid the possibility of causing further distress. Of the 1148 letters posted, 130 were returned undeliverable, therefore 1018 parents were assumed to have been contacted.

\section{Measures}

The study utilised a combination of published psychological measures, bereavementspecific questions and socio-demographic variables self-administered by the respondents.

Depression

Depression was measured using the 9-item Patient Health Questionnaire (PHQ-9) (Kroenke, Spitzer, \& Williams, 2001) which assesses probable psychiatric caseness for moderate to severe depression. The total score is used to indicate probable caseness, with a score of 10 or above suggesting moderate to severe depression (Spitzer, Kroenke, \& Williams, 1999). The scale was internally consistent in the current study (Cronbach's $\alpha=$ $.93)$.

Grief

The 19-item Inventory of Complicated Grief was used to assess clinical levels of grief (Prigerson et al., 1995). A score of 25 or over indicates that the participant meets the proposed diagnostic criteria for a clinical grief condition. The scale was internally consistent in the current study (Cronbach's $\alpha=.93$ ). 


\section{Trait Optimism/Pessimism}

The Life Orientation Test (Revised) LOT-R measures trait optimism/pessimism (Scheier, Carver, \& Bridges, 1994). The total score calculated from 6 items indicates the relative strength of trait optimism or pessimism. The scale was internally consistent in the current study for both optimism and pessimism (Cronbach's $\alpha=.83$ and .87 respectively).

\section{Coping Style}

Coping style was measured using the Brief Cope (Carver, Scheier, \& Weintraub, 1989), a 28-item questionnaire measuring 14 types of coping. The humour scale was removed from this study to avoid causing potential offence to participants. The remaining scales were aggregated into four summary sub-scales following O’Connor \& O’Connor (2003). Problem Focussed Coping (subscale one) was derived from the total scores from the Active Coping and Planning scales, Avoidance Focussed Coping (subscale two) was calculated from Denial and Behavioural Disengagement. Social Support (subscale three) was derived from the Seeking Instrumental Social Support and Seeking Emotional Social Support. Cognitive Restructuring (subscale four) was calculated from Positive Reinterpretation and Growth Acceptance. Self-blame, Use of Religion, Focus and Venting of Emotions and Alcohol and Substance Use did not readily lend themselves to any of these summary scales and were therefore retained as sub-scales in their own right. The internal consistency of the sub-scales was good (Problem Focussed Coping - Cronbach's $\alpha=.83$, Avoidance Coping - Cronbach's $\alpha=.78$, Social Support - Cronbach's $\alpha=.81$ and Cognitive Reconstruction Coping Cronbach's $\alpha=.74)$.

\section{Continuing Bonds}

Continuing Bonds were measured using the Continuing Bonds Scale (CBS) (Field, Gal-Oz, \& Bonanno, 2003). As the CBS was developed to assess continuing bonds following 
a spousal bereavement, the wording of the questions in this scale was changed from "spouse" to "child", for example, "I seek out things to remind me of my child". There are 11 questions in the scale with the participants responding on a scale from 1 (not at all true) to 5 (very true). The total score indicates the level of continuing bonds that the bereaved has with the deceased. The scale was internally consistent in the current study (Cronbach's $\alpha=.83$ ).

\section{Socioeconomic Status}

Postal (zip) codes are used in research in Scotland to estimate relative socioeconomic status (SES) as defined by a participant's postcode (McLoone, 2004). The scores are constructed using indices of poverty including level of overcrowding in the home, male unemployment, and no car ownership, as recorded in the Census statistics published by GROS. The postcodes given by the participants were checked against the list of all postcode areas in Scotland and their corresponding Carstairs score (index of deprivation was published by McLoone (2004). The scores were then collapsed into three categories to simplify comparisons, following Leyland, Dundas, McLoone and Boddy (2007). Those participants with scores 1 or 2 were described as Affluent, those with scores 3, 4 or 5 were described as Intermediate, and those with score 6 or 7 were described as Deprived.

\section{Education}

The options for education level were secondary school only, college, undergraduate or postgraduate. These were again collapsed into two categories - school or college and university (undergraduate or postgraduate), to simplify analysis.

\section{Cause of Death}

The cause of death being either violent or non-violent was derived from the underlying cause of death code supplied by GROS on the death records. Violent deaths were 
those which occurred as a result of accident, murder or suicide in line with previous research (e.g. Neimeyer, Baldwin \& Gillies, 2006). All others were classed as non-violent deaths.

\section{Death anticipation}

Parents were asked if their child's death was sudden or anticipated. Of the responses available, those specified as totally unexpected or expected in the hours before death were categorised as sudden and those that were expected for days or expected for some time were categorised as anticipated.

\section{Relationship status}

The options for relationship status were single, with partner, married, separated, divorced or widowed. These answers were summarised so that with partner or married was classified as "in a relationship". The other answers were classified as "not in a relationship".

\section{Employment status}

The options for employment status were unemployed, caring for family, sick, permanently disabled, training/studying, retired, working full time and working part time, the final two were classified as "working". All others were classified as "not working".

Two versions of the final questionnaires were created, with the order of questions reversed for counterbalancing to minimise order effects.

\section{Statistical Analyses}

Univariate logistic regression analyses were carried out, testing each of the categorical outcome variables with each of the predictors. Continuous variables were examined using linear regression, to determine which were significantly associated with the outcome variables. Only those variables which were found to be significant at $\mathrm{p}<.001$ were included in 
further multivariate analyses to identify the variables most likely to be important. Given the large number of potential predictors, a forward entry regression method was chosen to examine the relative importance of all significant factors, as recommended by Field (2009).

\section{Results}

Of the 1018 people contacted, 154 returned positive responses indicating they would like to take part in the research. Of these, 109 actually returned questionnaires. Three were only partly completed and were therefore 106 questionnaires were included in the analysis. Missing data were addressed using the method recommended from the WHOQOL Brief manual was used, i.e. "Where an item is missing, it is replaced with the mean of the other items in the scale (World Health Organization, 2011).

\section{Participant Demographics}

Comparisons were carried out using Chi-square tests between categorical variables such as sex of parent, sex of child, sudden or anticipated death, in the population list and those who participated in the study. Two notable differences were found. First, the proportion of mothers agreeing to take part in the research $(69 \%)$ was higher than that of the potential population $(52 \%), \chi^{2}(1)=6.05, p=.014$. This is consistent with previous research carried out with bereaved parents (e.g. Murphy, Tapper, Johnson \& Lohan, 2003; Woodgate, 2006).

Second, the number of participants in the deprived category was under-represented compared to the bereaved population, $\chi^{2}(2)=10.76, p=.005$.

The mean age of the child at time of death (9 years) was lower in the participants who completed the questionnaire compared to those who were in the population list (13 years), $\mathrm{t}(994)=4.07, \mathrm{p}<.001$. The mean age of parents who agreed to take part in the research was 42.8 years $(\mathrm{SD}=10.3)$. Age is not available from the data supplied by GROS, therefore this 
cannot be compared to the potential list of participants. Ninety-five participants $(90 \%)$ were married or in a relationship at the time of the bereavement. Eleven (10\%) were single, separated, divorced or widowed. Within the sample, 62 (59\%) had a basic high school or college education and $42(40 \%)$ were university graduates or had a postgraduate qualification. Two participants (2\%) did not supply their level of education.

The mean depression score for the group was $6.1, \mathrm{SD}=6.4$ with a range of $0-26$ (the maximum possible score being 27 ). The mean grief score was $22.4, \mathrm{SD}=15.4$, with a range of 2 - 62. The maximum possible grief score is 76 . More than half (54\%) of this group of bereaved parents met probable diagnostic criteria for a clinical grief disorder and $27 \%$ probable "caseness" for moderate or severe depression.

\section{Factors Associated with Increased Depression}

\section{Continuous Variables}

Linear regressions were run to identify those continuous variables which were univariately associated with higher depression scores. The factors significantly associated with higher depression scores at $\mathrm{p}<.001$ were avoidance focussed coping $(\mathrm{r}=.57)$, number of restoration stressors $(\mathrm{r}=.53)$, child age $(\mathrm{r}=.30)$ and continuing bonds score $(\mathrm{r}=.30)$.

\section{Categorical Variables}

Logistic regressions were carried out on the categorical variables, to determine which were associated with the classification of depression. None of the variables tested were significant at $\mathrm{p}<.001$.

\section{Relative Importance of Factors Associated with Increased Depression Scores}

The significant factors from the univariate analysis were then included in multivariate regressions test to establish which made the greatest contribution to explaining the variation 
in depression scores. A forward entry regression method was followed (Field, 2009), which produced a final model showing that avoidance-focussed coping accounted for $32 \%$ of the overall variation in depression scores, with number of restoration stressors accounting for a further $14 \%, F(2,99)=41,22, \mathrm{p}=<.001$.

\section{Factors Associated with Increased Grief}

\section{Continuous Variables}

Again, univariate linear regressions were run to establish which continuous variables were associated with higher grief scores. Those variables found to have a significant association were avoidance focussed coping $(\mathrm{r}=.66)$, number of restoration stressors $(\mathrm{r}=.55)$, child age $(\mathrm{r}=.45)$, continuing bonds score $(\mathrm{r}=.41)$, frequency of grave visitation (negative association $)(\mathrm{r}=.36)$ and parent age $(\mathrm{r}=.29)$.

\section{Categorical Variables}

Univariate logistic regressions were carried out on all of the categorical variables, to determine which were associated with the likely diagnosis of a clinical grief disorder. Again, none of the variables tested were significant at $\mathrm{p}<.001$.

\section{Relative Importance of Factors Associated with Increased Grief Scores}

The factors found to be significantly associated with higher grief scores were entered into a regression analysis with a forward method of analysis. The final model showed that three variables were associated with grief, accounting for $58 \%$ of the variation in scores, $\mathrm{F}(3,81)=37.91, \mathrm{p}<.001$. Avoidance-focussed coping accounted for $42 \%$ of the variance number of restoration stressors a further $12 \%$ and continuing bonds accounted for a further $4 \%$ of the variance in grief score. 


\section{Discussion}

Avoidance-focussed coping and the number of restoration-oriented stressors being experienced were found to be independently associated with depression symptoms in the multivariate analyses. The factors most strongly associated with grief were avoidancefocussed coping, number of restoration stressors and continuing bonds score.

\section{Avoidance}

Avoidance of attention to bereavement and its repercussions has been reliably found to predict clinical grief outcomes (e.g. Boelen, Stroebe et al., 2006) and psychological distress more broadly (O'Connor \& O'Connor, 2003) but was unexpectedly found not to be a significant mediator of risk factors for clinical outcomes in a recent large-scale study (van der Houwen, Streobe, Schut, Stroebe \& van der Bout, 2010). The results from the present study may reflect the method of participant recruitment as we invited participants directly from data held for death registrations, thereby avoiding the potential limitations of recruiting through support organisations or obituary notices. Research based on recruiting through these latter sources may not be accessing people who have avoided the bereavement or reminders of the loss. Further evaluation should be carried out to determine whether participant characteristics are influenced by the method of recruitment.

\section{Restoration-Oriented Stressors}

The seminal Dual Process Model of coping with bereavement (Stroebe et al., 1985) concludes that the process of bereavement requires an individual to attend to matters relating to the bereavement and to those stressors that are experienced as a result of the loss, for example, changes in financial circumstances, problems at work etc. The model is universally supported and endorsed by organisations supporting the bereaved, yet relatively little research has been carried out on how restoration stressors emerge and are managed by the bereaved individual. The present study indicates the importance of restoration-oriented stressors and, 
given that these are readily adaptable if appropriate policies are in force, they merit further investigation as a means of moderating the impact of bereavement on families.

\section{Continuing Bonds}

Continuing bonds have attracted significant research interest, however to date no measure has been found to reliably measure the different nuances and manifestations of a continuing bonds relationship (Stroebe, Schut \& Berner, 2009). The Continuing Bonds Scale was used in the present study, however this was adapted with bereaved partners in mind (Field et al., 2003). Some of the items in the scale may be more relevant in the loss of a partner (e.g. turning to the lost loved one for advice or carrying out the deceased's wishes) or may not include the types of continuing bonds such as symbolic representations which are typical for parents who experience the loss of a child (Harper, O'Connor, Dickson \& O'Carroll, 2009). Further research is needed before a reliable and validated scale can be used to measure the full range of continuing bond responses experienced by parents.

\section{Findings from Previous Research not Supported in the Present Study}

Earlier research identified factors which were univariately associated with grief symptoms. Time since death has previously been found to be associated with grief symptoms (Anderson et al., 2005) however its impact in the current study may have been reduced since the sample were drawn from a relatively small time frame (four to five years post-loss).

Social support (Hazzard et al., 1992) had previously been found to be associated with grief symptoms but was not found to be associated with lower levels of grief in the present study. Social support has been strongly supported as a buffer for grief symptoms in other types of loss and is recognised as one of the key factors for reducing the impact of bereavement (Stroebe et al., 2006). The impact of social support in the specific experience of parental bereavement therefore requires further investigation. 
The sex of the parent was considered important in previous research, with mothers experiencing higher levels of grief than fathers (Bohannon, 1991; Littlefield \& Silverman, 1991). In the present study there was no difference between grief and depression symptoms for mothers and fathers. Likewise, no difference was found in grief or depression symptoms related to the sex of the child and the loss of a male child did not elicit higher symptoms (Hazzard et al., 1992; Robinson \& Marwit, 2006). The present study included a relatively higher number of male participants than was seen in previous research and this may, therefore, have affected the findings. The risk factors for fathers and mothers merits further individual exploration in larger participant groups.

\section{Limitations of the Research}

The current research, as is the case in any where volunteers are required to take part, is potentially at risk of bias due to only a subsection of those eligible to participate agreeing to proceed. This risk is tempered, however, by the coverage of participant demographics, since those who took part in the current study appeared to be representative of those in the bereaved parent population in Scotland as a whole. There was over-representation of mothers in the current study, however this is a feature of much research with bereaved parents.

Additionally, those economically deprived were also under-represented and the experience of people having low socio-economic status should be reviewed further. In the present study, there was no consideration of ethnic identity or the impact of cultural background on the bereavement experience. This type of analysis should be carried out in an environment more culturally-diverse than that found within Scotland.

The present study recruited a small sample and its representativeness to the broader bereaved population is unclear. The sample indicate high levels of grief and depression, therefore the participants may represent those who are more prone to maladaptive coping compared to the general bereaved parent population. 


\section{Conclusions}

This study presents the findings from a detailed multivariate analysis of risk factors for grief and depression in a sample of bereaved parents with high levels of clinical grief symptoms and depression. Depression was predicted by avoidance-focussed coping and the number of restoration-oriented stressors. Grief was predicted by avoidance, restoration stressors and level of continuing bonds. These findings provide partial support for the proposed Integrative Risk Factor Framework in the grief of bereaved parents and indicate areas which require further exploration, for example, why social support appeared relatively unimportant compared to other risk factors? Further research to explore some of these factors in greater details is essential if the experience of parental bereavement is to be fully understood. 
References

Anderson, M., Marwit, S.J., Vandenberg, B., \& Chibnall, J. (2005). Psychological and religious coping strategies of mothers bereaved by the sudden death of a child. Death Studies, 29(9), 811-826.

Bohannon, J.R. (1991). Grief Responses of Spouses Following the Death of A Child - A Longitudinal-Study. Omega-Journal of Death and Dying, 22(2), 109-121.

Carver, C.S., Scheier, M.F., \& Weintraub, J.K. (1989). Assessing Coping Strageies: A Theoretically Based Approach. Journal of Personality and Social Psychology, $56(2), 267-283$.

Currier, J.M., Holland, J.M., \& Neimeyer, R.A. (2006). Sense-making, grief, and the experience of violent loss: toward a mediational model. Death Studies, 30(5), 403428.

Feigelman, W., Gorman, B.S., \& Jordan, J.R. (2009). Stigmatization and Suicide Bereavement. Death Studies, 33(7), 591-608.

Field, A. (2009). Discovering Statistics Using SPSS - 3rd edition. London: Sage.

Field, N., Gal-Oz, E., \& Bonanno, G.A. (2003). Continuing bonds and adjustment at 5 years after the death of a spouse. Journal of Consulting and Clinical Psychology, 71(1), 110-117.

Harper, M., O'Connor, R.C., \& O'Carroll, R.E. (under review). Grief Associated with Higher Likelihood of Social Problems and Distinct from Depression in Bereaved Parents. The Lancet.

Hazzard, A., Weston, J., \& Gutterres, C. (1992). After A Childs Death - Factors Related to Parental Bereavement. Journal of Developmental and Behavioral Pediatrics, 13(1), 24-30.

Ito, T., Tomita, T., Hasui, C., Otsuka, A., Katayama, Y., Kawamura, Y. (2003). The link between response styles and major depression and anxiety disorders after childloss. Comprehensive Psychiatry, 44(5), 396-403.

Kroenke, K., Spitzer, R.L., \& Williams, J.B. (2001). The PHQ-9 - Validity of a Brief Depression Severity Measure. Journal of General International Medicine, 16, 606613.

Leyland, A.H., Dundas, R., McLoone, P., \& Boddy, F.A. (2007). Cause-specific inequalities in mortality in Scotland: two decades of change. A population-based study. BMC Public Health, 7(172), -.

Littlefield, C.H., \& Silverman, I. (1991). Marital dissatisfaction following the death of a child: the influence of genetic factors at cause in the death. Journal of Marriage and the Family, 53(3), 799-804.

McLoone, P. (2004). Carstairs scores for Scottish postcode sectors from the 2001 Census. Glasgow: MRC Social \& Public Health Sciences Unit.

Morrison, R., \& O'Connor, R.C. (2008). A systematic review of the relationship between rumination and suicidality. Suicide and Life-Threatening Behavior, 38(5), 523538.

Neimeyer, R.A., Baldwin, S.A., \& Gillies, J. (2006). Continuing bonds and reconstructing meaning: Mitigating complications in bereavement. Death Studies, 30(8), 715-738.

Nolen-Hoeksema, S. (1991). Responses to depression and their effects on the duration of depressive episodes. Journal of Abnormal Psychology, 100, 569-582. 
Nolen-Hoeksema, S., Parker, L.E., \& Larson, J. (1994). Ruminative Coping with Distressed Mood Following Loss. Journal of Personality and Social Psychology, 67(1), 92-104.

Prigerson, H.G., Maciejewski, P.K., Reynolds, C.F., Bierhals, A.J., Newsom, J.T., Fasiczka, A. (1995). Inventory of complicated grief: a scale to measure maladaptive symptoms of loss. Psychiatry Research, 59, 6-79.

Rando, T.A. (1983). An investigation of grief and adaptation in parents whose children have died from cancer. Journal of Pediatric Psychology, 8(1), 3-20.

Robinson, T., \& Marwit, S.J. (2006). An investigation of the relationship of personality, coping, and grief intensity among bereaved mothers. Death Studies, 30(7), 677696.

Scheier, M.F., Carver, C.S., \& Bridges, M.W. (1994). Distinguishing optimism from neuroticism (and trait anxiety, self-mastery, and self-esteem): A reevaluation of the Life Orientation Test. Journal of Personality and Social Psychology, 67, 10631078.

Spitzer, R.L., Kroenke, K., \& Williams, J.B.W. (1999). Validation and utility of a selfreport version of PRIME-MD - the PHQ Primary Care Study. Journal of the American Medical Association, 282(18), 1737-1744.

Stroebe, M., Boelen, P.A., van den Hout, M., Stroebe, W., Salemink, E., \& van den Bout, J. (2007). Ruminative coping as avoidance - A reinterpretation of its function in adjustment to bereavement. European Archives of Psychiatry and Clinical Neuroscience, 257(8), 462-472.

Stroebe, M., \& Schut, H. (1999). The dual process model of coping with bereavement: rationale and description. Death Studies, 23(3), 197-224.

Stroebe, M.S., Folkman, S., Hansson, R.O., \& Schut, H. (2006). The prediction of bereavement outcome: Development of an integrative risk factor framework. Social Science \& Medicine, 63(9), 2440-2451.

Stroebe, M.S., Schut, H., \& Stroebe, W. (2007). Health outcomes of bereavement. Lancet, 370, 1960-1973.

Stuckler, D., Basu, S., Suhrcke, M., Coutts, A., \& McKee, M. (2011). Effects of the 2008 recession on health: a first look at European data. The Lancet, 378(9786), 124125.

Wijngaards-de-Meij, L., Stroebe, M., Schut, H., Stroebe, W., van den Bout, J., van der Heijden, P. (2005). Couples at Risk Following the Death of Their Child: Predictors of Grief Versus Depression. Journal of Consulting and Clinical Psychology, 73(4), 617-623.

World Health Organization. (2011). WHOQOL-BREF - Introduction, Administration, Scoring of the Generic Version of the Assessment, http://www.who.int/mental_health/media/en/76.pdf accessed 6th June 2011. 